\title{
Control of Browning of Yam (dioscorea rotundata) and Sweet potato (Ipomoea batatas) using African Cardamon (Aframomum danielli), Turmeric (Curcuma longa) and Clove (Syzygiumnn aromaticum)
}

\author{
G. O. Adegoke \& A. O. Odebade \\ Department of Food Technology \\ University of Ibadan, Nigeria \\ M. O. Afolabi (Corresponding author) \\ Department of Food Science and Technology \\ Bowen Univetrsity, Iwo, Nigeria \\ E-mail: afolabiolutoyin@gmail.com
}

Received: September 29, 2017 Accepted: November 20, 2017 Published: December 10, 2017 doi:10.5296/jfi.v1i1.12277

URL: http://dx.doi.org/10.5296/jfi.vli1.12277

\begin{abstract}
This study was carried out to evaluate the effect of using the aqueous extracts of Aframomum danielli, Turmeric and Clove at different concentrations of 5\%, 10\% and $15 \%$ as pretreatments in controlling browning of yam (Dioscorea rotundata) and sweet potato (Ipomoea batatas). Colour measurements were carried out on the untreated (control) and pretreated yam and sweet potato slices, using reflectance spectroscopy. The $\mathrm{L}^{*}$ and a* values obtained for the control samples were compared with those of the pretreated yam and sweet potato samples. The inhibition of enzymatic browning in the samples was indicated by an increase in the " $L^{*}$ " values which ranged from 81.60 to 62.66 for yam samples and from 81.52 to 62.03 for sweet potato samples; browning was also associated to a decrease in the " $a *$ " values for all the samples, which ranged from 4.29 to -1.86 for yam samples and 4.02 to -2.46 for sweet potato samples. Aqueous extracts of Aframomum danielli at minimum concentrations of $5 \%$ and $10 \%$ were found to be effective in controlling browning reactions
\end{abstract}


in the pretreated yam slices and sweet potato slices respectively.

Keywords: Browning, Aframomum danielli, Turmeric, Clove, Yam, Sweet potato

\section{Introduction}

Yam belongs to the genus Dioscorea of the family Dioscoreaceae; which has about 600 species of which D. alata (water yam); D. cayenensis (yellow yam), and D. rotundata (white yam), has the greatest economic importance (Falade, Olurin, Ike, and Aworh 2007). United Nation's Food and Agriculture Organization (FAO) (2011) reported that sweet potato (Ipomea batatas) is also a very important crop in the developing world and a traditional, but less important crop in some parts of the developed world. The major processing problem for both sweet potato and yams (white yam $D$. rotundata) is the browning resulting from enzymatic and non-enzymatic reactions. Enzymatic browning caused by the oxidation of phenols by polyphenol oxidases and peroxidases is the most common phenomenon associated with the browning of yams and sweet potato during injury and processing at low temperatures (Teo, Lasekan, Adzahan and Hashim, 2016). Consequently, the control of enzymatic browning in order to maintain their quality, nutritional value and safety has aroused strong interest in the food industry (Krishnan, Padmaja, Moorthy, Suja and Sajeev, 2010). One approach to the prevention of this phenomenon has been the use of anti-browning agents such as sulphite containing additives (Egwim, Gajere and Bello, 2013), ascorbic acid, acetic acid, citric acid etc. (Krishnan et al., 2010). However, due to health concerns, sulphites use has been restricted (Anon, 1991).

The use of natural occurring materials as preservatives is a promising alternative to the use of chemicals (Howell, 1986). The potential sources of natural preservative are spices, herbs, fruits, seed, leaves, barks and roots (Pratt and Hudson, 1996). According to Babarinde, Adegoke and Akinoso (2014), the use of organic products such as spices with antioxidant and antimicrobial properties can serve as alternative control methods. Yapi, Dabonné, and Kouamé, (2015) reported the inhibitory effect of onions and garlic extract on the enzymatic browning of an edible yam (Dioscorea cayenensis-rotundatacv. Kponan) cultivated in Côted'Ivoire. Aframomum danielli extract has potential as a preservative in food system (;Adegoke, Evwiehurhoma and Afolabi, (2016)).Similarly, Turmeric and Clove are well known for their antioxidant, antimicrobial and anti-carcinogenic properties in food system(Agbaje, Adeneye, and Daramola, 2009; Virendra, Shalini, Nirmala, Chetan, and Kalpagam, 2013). The objective of this study was to evaluate the efficacy of aqueous extracts of Aframomum danielli, Curcumi longa and Syzygium aromaticum in controlling browning of yam and sweet potato.

\section{Materials and Methods}

White Yam (Dioscorea rotundata) and Sweet Potato (Ipomoea batatas) tubers as well as Spices Aframomum danielli, Turmeric (Curcuma longa) and Clove (Syzygium aromaticum) were purchased at Bodija market, Ibadan, Oyo state. Dried Aframomum danielli seeds and flower buds of Clove were winnowed, cleaned and milled after purchase. Also, the turmeric rhizomes were washed, drained, cut into pieces, dried and milled. Powder was then stored in 


\section{Macrothink}

air tight, light shielded container to prevent escape of volatile compound. The method described by Adegoke, Makinde, Falade and Uzo Peters, (2003) was used to prepare the aqueous extracts of Aframomum danielli, Turmeric and Clove. 5\%, 10\% and 15\% concentration of each spice was prepared by dissolving $5 \mathrm{~g}, 10 \mathrm{~g}$ and $15 \mathrm{~g}$ in $100 \mathrm{ml}$ of sterile distilled water. The suspension was kept at $4^{0} \mathrm{C}$ for 5 days, centrifuged at $10,000 \mathrm{rpm}$ for 10 minutes. The supernatant was collected and stored for use.

\subsection{Anti-browning Treatment}

Each tuber was washed, peeled, cut and chipped with a manual hand chipper to an average thickness of about $3.3 \mathrm{~mm}$. The slices were blanched, steeped in water (untreated control) or aqueous extracts of each spice at different concentrations of 5\%,10\% and $15 \%$ for 10 minutes, after which they were drained and held at room temperature (Adegoke et al., 2016) during which colour measurement was carried out, using reflectance spectroscopy.

The colour of the chips was measured using a Minolta portable Chroma-meter. Readings were recorded for the untreated (control), blanched and each of the samples treated with $A$. danielli, Turmeric and Clove at 5\%,10\% and 15\%. The hunter lab colour coordinates system; Lightness $\left(\mathrm{L}^{*}\right)$, redness $\left(\mathrm{a}^{*}\right.$, red-green) and yellowness $\left(\mathrm{b}^{*}\right.$, yellow-blue) values were measured after treatment(Mohammadi, Rafie, Emam-Djomeh, and Keyhani, 2008). The samples were run in triplicates. Other colour parameters associated with this colour scale were determined using the mean of the measured values and calculated using Microsoft Excel 2010 .

Chroma $=\left(\mathrm{a}^{2}+\mathrm{b}^{* 2}\right)^{0.5}($ Giese, 2000$)$

Hue angle $=\tan ^{-1}\left(\frac{\mathrm{bs}}{\mathrm{a}}\right)$ (Mohammadi et al., 2008)

The brown index was calculated as (100-L*) (,Jimoh, Olurin and Aina 2009).

\subsection{Statistical Analysis}

All data obtained from various analysis were subjected to analysis of variance (ANOVA) using the Statistical Package for Social Science (SPSS) version 16.0. Means were separated using new Duncan's multiple range tests at 95\% confidence level $(\mathrm{p}<0.05)$. Determinations were carried out in triplicates and duplicates. Microsoft Excel (2010) was also used for calculations and graphical representations of data.

\section{Results and Discussion}

\subsection{Effect of Aframomum danielli, Turmeric and Clove on Browning}

Generally, aqueous extracts of Aframomum danielli at the different concentrations were considered to be very effective in controlling browning reactions in the samples. The aqueous extracts of Tumeric at the different concentrations were not as effective as aqueous extracts of A. danielli in controlling browning in the different samples. The aqueous extracts of clove at $5 \%, 10 \%$ and $15 \%$ were not effective, as the $L^{*}, a^{*}$ and $b^{*}$ values gotten from the colour 


\section{Macrothink

measurement, showed that the samples had the lowest lightness value, compared with the Control sample. Also, the blanched sample was observed to have reduced lightness value. A decrease in $L^{*}$ value and an increase in $a^{*}$ value are indicative of browning; increases in $L^{*}$ values and decreases in $a^{*}$ values are indicative of the antibrowning effect of browning inhibitors (Adegoke et al., 2016). s

As shown in Table 1, sample with5\% A. danielli had the highest $L$ value of 81.60 , while the one with $15 \%$ A. danielli had the lowest $L$ value of 62.66. Similarly, ' $a$ ' values ranged from $4.29(10 \% \mathrm{~A}$. danielli) to -1.86 (blanched sample), while $b$ values ranged from 23.56 (for sample containing $10 \% \mathrm{~A}$. danielli) to 13.44 (untreated sample). Aqueous extracts of Aframomum danielli at 5\%,10\% and $15 \%$ are therefore considered to be more effective in inhibiting browning reactions in yam slices. This is in line with the findings of Adegoke et al. (2016) that A. danielli can compare favourably with other food grade anti-browning agents, due to active natural antioxidants present in the spice.

For the pretreated sweet potato slices, as shown in Table 2, no significant difference was noted between the control sample and sample with $10 \%$ A.danielli and they had the highest $L$ values of 81.75 and 81.52 respectively, while the sample containing $15 \%$ clove had the lowest $L$ value of 62.03. " $a$ " values ranged from 4.02 (in a sample with $15 \%$ clove) to -2.46 (sample with 10\% A.danielli); " $b$ " values ranged from 22.83 (in the sample with $15 \%$ clove) to 17.93 (untreated sanple). Aqueous extract of $10 \%$ Aframomum danielli was found to be effective in controlling browning reactions in all the samples.

Generally, Higher $L^{*}$ value indicated whiter yam slices, and lower brown index $(100-L)$. The calculated Chroma value, Hue angle measured from the $L^{*}, a^{*}, b^{*}$ parameters showed that Chroma values ranged from 13.46(in the untreated sample) to 23.95(in sample containing $10 \%$ A. danielli) for yam slices and 18.00 (untreated sample) to 23.18 ( sample with $15 \%$ clove) for sweet potato slices while Hue angle of the samples ranged from 79.68 (sample preserved with $15 \%$ clove) to 95.60 (sample containing $15 \%$ A. danielli) for yam slices and 80.01 (ECP) to 96.46 (TAP) for sweet potato slices The higher the Chroma value, the higher the colour intensity, and also suggests possible increased browning of the samples. On the other hand, the hue angles are within the normal range, expected of yam slices (white-yellow $\leq 90$ ) (Opara et al., 2013). 


\section{1) Macrothink}

Table 1. Colour Parameters of Untreated and Pretreated Yam Slices.

\begin{tabular}{|c|c|c|c|c|c|c|}
\hline SAMPLES & $\mathbf{L}^{*}$ & $a^{*}$ & $\mathbf{b}^{*}$ & $\begin{array}{l}\text { Chroma } \\
\text { value }\end{array}$ & $\begin{array}{l}\text { Hue } \\
\text { angle }\end{array}$ & $100-L^{*}$ \\
\hline Untreated & $80.65 \pm 0.02^{\mathrm{c}}$ & $-0.74 \pm 0.01^{\mathrm{g}}$ & $13.44 \pm 0.01^{\mathrm{k}}$ & 13.46 & 93.15 & 19.35 \\
\hline Blanched & $75.13 \pm 0.13^{\mathrm{h}}$ & $-1.86 \pm 0.01^{\mathrm{j}}$ & $19.16 \pm 0.01^{\mathrm{g}}$ & 19.25 & 95.54 & 24.87 \\
\hline A. danielli: $5 \%$ & $81.60 \pm 0.02^{\mathrm{a}}$ & $-0.49 \pm 0.01^{\mathrm{d}}$ & $14.78 \pm 0.01^{\mathrm{j}}$ & 14.79 & 91.90 & 18.40 \\
\hline $10 \%$ & $80.48 \pm 0.05^{\mathrm{d}}$ & $-0.65 \pm 0.01^{\mathrm{e}}$ & $16.56 \pm 0.00^{\mathrm{i}}$ & 16.57 & 92.25 & 19.52 \\
\hline $15 \%$ & $81.47 \pm 0.02^{\mathrm{b}}$ & $-1.79 \pm 0.01^{\mathrm{i}}$ & $18.26 \pm 0.01^{\mathrm{h}}$ & 18.35 & 95.60 & 18.53 \\
\hline Tumeric: 5\% & $78.10 \pm 0.11^{\mathrm{e}}$ & $-0.91 \pm 0.00^{\mathrm{h}}$ & $21.45 \pm 0.03^{\mathrm{e}}$ & 21.47 & 92.43 & 21.90 \\
\hline $10 \%$ & $77.14 \pm 0.01^{\mathrm{g}}$ & $-0.71 \pm 0.01^{\mathrm{f}}$ & $22.15 \pm 0.05^{\mathrm{c}}$ & 22.16 & 91.84 & 22.86 \\
\hline $15 \%$ & $77.24 \pm 0.01^{\mathrm{f}}$ & $-0.63 \pm 0.01^{\mathrm{e}}$ & $22.36 \pm 0.00^{\mathrm{b}}$ & 22.37 & 91.61 & 22.76 \\
\hline Clove : & $65.30 \pm 0.04^{\mathrm{i}}$ & $3.17 \pm 0.02^{\mathrm{c}}$ & $22.06 \pm 0.01^{\mathrm{d}}$ & 22.29 & 81.82 & 34.70 \\
\hline $10 \%$ & $62.89 \pm 0.04^{\mathrm{j}}$ & $4.29 \pm 0.03^{\mathrm{a}}$ & $23.56 \pm 0.01^{\mathrm{a}}$ & 23.95 & 79.68 & 37.11 \\
\hline $15 \%$ & $62.66 \pm 0.01^{\mathrm{k}}$ & $3.63 \pm 0.01^{\mathrm{b}}$ & $21.05 \pm 0.01^{\mathrm{f}}$ & 21.36 & 80.22 & 37.34 \\
\hline
\end{tabular}

Note. Means $\pm \mathrm{S}$. D along each row with different superscript are significantly different with $\mathrm{a}>\mathrm{b}>\mathrm{c}>\ldots>\mathrm{k}$; mean separation done with Duncan Multiple Range test and Means followed by the same letter within a column do not differ significantly $(\mathrm{P}<0.05)$

Table 2: Colour Parameters of Untreated and Treated Sweet Potato Slices

\begin{tabular}{|c|c|c|c|c|c|c|}
\hline . & $\mathbf{L}^{*}$ & $a^{*}$ & $\mathbf{b}^{*}$ & $\begin{array}{l}\text { Chroma } \\
\text { value }\end{array}$ & Hue angle & $100-L^{*}$ \\
\hline Untreated & $81.75 \pm 0.02^{\mathrm{a}}$ & $-1.53 \pm 0.01^{\mathrm{e}}$ & $17.93 \pm 0.01^{\mathrm{k}}$ & 18.00 & 94.88 & 18.25 \\
\hline Blanched & $71.57 \pm 0.52^{\mathrm{g}}$ & $-1.61 \pm 0.09^{\mathrm{f}}$ & $19.41 \pm 0.14^{\mathrm{j}}$ & 19.48 & 94.74 & 28.43 \\
\hline A.danielli:5\% & $79.38 \pm 0.06^{\mathrm{d}}$ & $-1.10 \pm 0.00^{\mathrm{d}}$ & $21.82 \pm 0.01^{\mathrm{c}}$ & 21.85 & 92.89 & 20.62 \\
\hline $10 \%$ & $81.52 \pm 0.05^{\mathrm{a}}$ & $-2.46 \pm 0.02^{\mathrm{h}}$ & $21.74 \pm 0.01^{\mathrm{d}}$ & 21.88 & 96.46 & 18.48 \\
\hline $15 \%$ & $80.30 \pm 0.01^{\mathrm{b}}$ & $-1.81 \pm 0.01^{\mathrm{g}}$ & $19.51 \pm 0.01^{\mathrm{i}}$ & 19.59 & 95.30 & 19.70 \\
\hline Tumeric: 5\% & $79.67 \pm 0.11^{\mathrm{c}}$ & $-1.51 \pm 0.01^{\mathrm{e}}$ & $20.76 \pm 0.04^{\mathrm{g}}$ & 20.81 & 94.16 & 20.33 \\
\hline $10 \%$ & $78.34 \pm 0.01^{\mathrm{e}}$ & $-1.55 \pm 0.01^{\mathrm{e}}$ & $20.36 \pm 0.01^{\mathrm{h}}$ & 20.42 & 94.35 & 21.66 \\
\hline $15 \%$ & $77.48 \pm 0.03^{\mathrm{f}}$ & $-1.08 \pm 0.01^{\mathrm{d}}$ & $22.01 \pm 0.00^{\mathrm{b}}$ & 22.04 & 92.81 & 22.52 \\
\hline Clove: $5 \%$ & $68.30 \pm 0.09^{\mathrm{h}}$ & $2.46 \pm 0.03^{\mathrm{c}}$ & $21.62 \pm 0.03^{\mathrm{e}}$ & 21.76 & 83.51 & 31.70 \\
\hline $10 \%$ & $66.36 \pm 0.02^{\mathrm{i}}$ & $2.56 \pm 0.01^{\mathrm{b}}$ & $21.19 \pm 0.01^{\mathrm{f}}$ & 21.34 & 83.11 & 33.64 \\
\hline $15 \%$ & $62.03 \pm 0.06^{\mathrm{j}}$ & $4.02 \pm 0.03^{\mathrm{a}}$ & $22.83 \pm 0.01^{\mathrm{a}}$ & 23.18 & 80.01 & 37.97 \\
\hline
\end{tabular}

Note. Means $\pm \mathrm{S}$. D along each row with different superscript are significantly different with $\mathrm{a}>\mathrm{b}>\mathrm{c}>\ldots>\mathrm{k}$; mean separation done with Duncan Multiple Range test and Means followed by the same letter within a column do not differ significantly $(\mathrm{P}<$

\section{Conclusion}

The aqueous extracts of $A$. danielli at different concentrations had significant effects in controlling browning of yam and sweet potato chips. A. danielli treatments were more 
effective than either of the Turmeric and Clove treatments. Generally, the results obtained from screening of the different plant extracts confirmed the potency of these spices and their use in food processing, storage and preservation. It can therefore be concluded that aqueous extracts of A. danielli can be used in controlling browning of Yam (Dioscorea rotundata) and Sweet potato (Ipomoea batatas).

\section{References}

Adegoke, G. O., Makinde, O., Falade, K. O. and Uzo Peters, P. I. (2003). Extraction and characterization of antioxidants from Aframomum melegueta and Xylopia aethiopica. European Food Res. Technol, (216), 526-528. https://doi.org/10.12691/ajfst-2-4-2

Adegoke, G. O., Evwiehurhoma, F.O., Afolabi, M O., (2016). African Cardamom (Aframomum danielli) Oils. In V. R. Preedy, (Ed.), Essential Oils in Food Preservation (pp. 161-170). Flavor and Safety. Academic Press, London. https://doi.org/10.1016/B978-0-12-416641-7.00017-1

Agbaje, E. O., Adeneye, A. A., \& Daramola, A. O. (2009). Biochemical and Toxicological Studies of Aqueous Extract of Syzigium Aromaticum (L.) Merr. \& Perry (Myrtaceae) In Rodents Afr. J. Trad. 6.(3) 241 - 254. Retrieved December, 2017, from http://www.ncbi.nlm.nih.gov>.pumed

Anon. (1991). Sulphites banned. Proc. Food Ingredients Int., (11), 1111.

Babarinde, G. O., Adegoke, G. O., \& Akinoso, R. (2014). Effect of Aframomum danielli extract on some chemical and antioxidant components of Roma Tomato Variety during storage. American Journal of Food Technology, 9(1), 28-38. https://doi.org/10.3923/ajft.2014.28.38

Egwin, E. C., Gajere, Y., \& Bello, T. (2013). Evaluation of Ascorbic Acid and Sodium Metabisulphite as Inhibitors of Browning in Yam (D. rotundata) Flour Processing Annals Food Science and Technology 1-14. Retrieved December, 2017 from https://www.afst.valahia.ro

Falade, K.O., Olurin, T.O., Ike, E. A. and Aworh O. C. (2007). Effect of pretreatment and temperature on air-drying of Dioscorea alata and Dioscorea rotundata slices. Journal of Food Engineering, (80), 1002-1010. https://doi.org/10.1016/j.jfoodeng.2006.06.034

Giese, J. (2000). Colour measurement in Foods as a Quality Parameter. Food Technology, $54(2), 62-65$.

Jimoh, K. O., Olurin, T. O. and Aina, J. O. (2009). Effect of drying methods on the rheological characteristics and colour of yam flours. African Journal of Biotechnology, 8(10), 2325-2328.

Jyothi G.K., Padmaja, G, Moorthy, S. N., Suja, G. and Sajeeve, M. S. (2010). Efffect of pre soaking treatments on the nutritional profile and browning index of sweet potato and yam flours. Innovative Food Science \& Emerging Technologies. 11(2), 387-393. https://doi.org/10.1016/j.ifset.2010.01.001 
https://doi.org/10.1016/j.ifset.2010.01.001

Krishnan, J. G., Padmaja, G., Moorthy, S. N., Suja, G., \& Sajeeve, M. S. (2010). Effect of pre-soaking treatments on the nutritional profile and browning index of sweet potato and yam flours. Journal of Innovative food science and emerging technologies, 11(2), 387-393. https://doi.org/10.1016/j.ifset.2010.01.010

Mohammadi, A., Rafie, S., Emam-Djomeh, Z., \& Keyhani, A. (2008). Kinetic Models for Color Changes in Kiwifruit Slices During Hot Air Drying. World Journal of Agricultural Sciences, 4(3), 376-383. Retrieved December, 2017 from http://www.idosi.org >wjas>wjas4

Opara, L. U., Pathare, B. P., \& Al-Said, F. A. (2013) Colour Measurement and Analysis in Fresh and Processed Foods: A Review. F ood Bioprocess Technology, (6), 36-60.

Orhevba, B. A., \& Osunde, Z. D.(2006). Effect of Storage condition and CIPC treatment on sprouting and weight loss of stored yam tubers. Proceedings of the Seventh International Conference and 28th Annual General Meeting of the Nigerian Institutions of Agricultural Engineers held at Zaria, Kaduna State. Retrieved December, 2017 from http://www.academicjournals.org/jspprh

Pratt, D. E., \& Hudson, B. J. F. (1996). Natural antioxidants not exploited commercially. In: Food Antioxidants (B. J. F. Hudson, ed). Elsevier Applied Science, New York 171. https://doi.org/10..1007/s13197-016-2275-z

Teo, L. S. „Lasekan, O., Adzahan, N. M., \& Hashim, N.(2016). The effect of ultraviolet treatment on enzymatic activity and total penolic content of minimally processed potato slices. Journal of Food Science and Technology, 53(7), 3035-3042. https://doi.org/10.1007/s13197-016-2275-z

Virendra, V. P., Shalini, T., Nirmala, K., Chetan, N. and Kalpagam, P. (2013). In vitro evaluation on antioxidant and antimicrobial activity of spice extracts of ginger, turmeric and garlic. Journal of Pharmacognosy and Phytochemistry, 2(3) 143-148. Retrieved December, 2017 from http://www.researjjchgate.net/publication/258022434

Yapi, J. C., Gnangui, S. N., Dabonné, S., \& Kouamé, L. P. (2015). Inhibitory Effect of Onions and Garlic Extract on the Enzymatic Browning of an Edible Yam (Dioscorea cayenensis-rotundata cv. Kponan) cultivated in Côte d'Ivoire. International Journal of Current Research Academic Review, 3(1), 219-231. Retrieved December, 2017 from http://www.ijcrar.com

\section{Copyright Disclaimer}

Copyright for this article is retained by the author(s), with first publication rights granted to the journal.

This is an open-access article distributed under the terms and conditions of the Creative Commons Attribution license (http://creativecommons.org/licenses/by/3.0/). 